\title{
Spinal Dermoid and Epidermoid Cyst: An Institutional Experience and Clinical Insight into the Neural Tube Closure Models
}

\author{
Ved P. Maurya ${ }^{1} \quad$ Yashveer Singh ${ }^{1} \quad$ Arun K. Srivastava ${ }^{1} \quad$ Kuntal K. Das ${ }^{1} \quad$ Kamlesh S. Bhaisora ${ }^{1}$ \\ Jayesh Sardhara ${ }^{1}$ Sanjay Behari ${ }^{1}$ \\ ${ }^{1}$ Department of Neurosurgery, Sanjay Gandhi Post Graduate \\ Institute of Medical Sciences, Lucknow, Uttar Pradesh, India

\begin{abstract}
Address for correspondence Arun K. Srivastava, MCh, Department of Neurosurgery, First Floor, C- Block (Hospital Building), Sanjay Gandhi Post Graduate Institute of Medical Sciences, Raebareli Road, Lucknow, Uttar Pradesh 226014, India (e-mail: doctorarunsrivastava@gmail.com).
\end{abstract}

\begin{abstract}
Objectives The spinal dermoid and epidermoid cysts (SDECs) are rare entities comprising less than $1 \%$ of pediatric intraspinal tumors. The present study aims to extrapolate the clinicoradiological data, in order to identify the most plausible neural tube closure model in human and provide a retrospective representation from our clinical experience.

Materials and Methods We collected the details of all histologically proven, newly diagnosed primary SDECs who underwent excision over the past 20 years. Secondary or recurrent lesions and other spinal cord tumors were excluded. Surgical and follow-up details of these patients as well as those with associated spinal dysraphism were reviewed. Clinical and radiological follow-up revealed the recurrence in these inborn spinal cord disorders.

Results A total of 73 patients were included retrospectively, having a mean age of $22.4 \pm 13.3$ years, and $41(56.2 \%)$ cases fell in the first two decades of life. Twentyfour $(32.9 \%)$ dermoid and 49 (67.1\%) epidermoid cysts comprised the study population and 20 of them had associated spinal dysraphism. The distribution of SDECs was the most common in lumbosacral region $(n=30)$ which was 10 times more common than in the sacral region $(n=3)$. Bladder dysfunction $50(68.5 \%)$ and pain $48(65.7 \%)$ were the most common presenting complaints. During follow-up visits, $40 / 48(83.3 \%)$ cases

Keywords

- spinal cord tumor

- spinal dysraphism

- dermoid

- epidermoid

- bladder dysfunction showed sensory improvement while $11 / 16$ (68.7\%) regained normal bowel function. There was no surgical mortality with recurrence seen in eight till the last follow-up.

Conclusions The protracted clinical course of the spinal inclusion cysts mandates a long-term follow-up. The results of our study support the multisite closure model and attempt to provide a retrospective reflection of neural tube closure model in humans by using SDECs as the surrogate marker of neural tube closure defect.
\end{abstract}

published online

March 24, 2021
DOI https://doi.org/

$10.1055 / \mathrm{s}-0041-1724229$ ISSN 0976-3147.
(C) 2021. Association for Helping Neurosurgical Sick People. This is an open access article published by Thieme under the terms of the Creative Commons Attribution-NonDerivative-NonCommercial-License, permitting copying and reproduction so long as the original work is given appropriate credit. Contents may not be used for commercial purposes, or adapted, remixed, transformed or built upon. (https://creativecommons.org/licenses/by-nc-nd/4.0/). Thieme Medical and Scientific Publishers Pvt. Ltd. A-12, 2nd Floor, Sector 2, Noida-201301 UP, India 


\section{Introduction}

The spinal dermoid and epidermoid cysts (SDECs) are rare ailments, comprising approximately 0.2 to $1 \%$ of all spinal tumors. ${ }^{1}$ We believe that the clinical and radiological details of a congenital disease associated with neural tube closure defect can probably contribute and support the various proposed neural tube closure models. It has been proven that the primary neurulation in human is different not only from avian models but also from other class of mammals like a pig. ${ }^{2-5}$

The mechanism of the closure of human neural tube was relatively unchallenged till recently and was described as a continuous closure model where the closure begins between the 3rd and 6th somite (future neck area) and thereafter continue bidirectionally in a zipper-like manner toward the rostral and caudal ends. The differential fusion of surface ectoderm and neural ectoderm along with disturbances in their separation leads to mesodermal defects and dorsal inclusion cysts (like epidermoid and dermoid cysts). ${ }^{6}$ Nearly three decades back, the mechanism of continuous closure model was doubted by a few researchers in this field. Van Allen et al proposed a "multisite closure model," which was further refined by Nakatsu et al in the year 2000 after his splendid work on 68 human embryos from the Kyoto collection.?

\section{Materials and Methods}

\section{Inclusion Criteria}

This retrospective observational study was conducted in the Department of Neurosurgery, a tertiary care referral center, and the study was approved by the institutional ethics committee (IEC code: 2020-275-IP-EXP-31).

We collected the clinical and radiological details of all histologically proven, newly diagnosed primary SDECs who underwent surgical intervention over the past 20 years, that is, from January 2000 to January 2020.

\section{Exclusion Criteria}

Those cases who were found to have the following:

- Secondary/implantation dermoid and epidermoid following trauma or repeated lumbar puncture.

- Other spinal cord tumors.

- Nonconclusive biopsy.

- Recurrent and residual lesions.

\section{Methodology}

The SDECs indexed with ICD coding 133.00, spinal dysraphism with associated dermoid, and epidermoid indexed with ICD coding 22.00 to 28.00 were recorded. The detailed clinical, radiological, operative and postoperative follow-up data were recorded from the hospital information and record-keeping system. Specific details included: documentation of symptom complex, associated mesodermal defects, neurocutaneous stigmata of spinal dysraphism and associated orthopaedic deformity (if any) at the time of admission and subsequent follow-up visits. As per protocol, all the patients of spinal dysraphism undergo a detail urological assessment which includes cystometrogram, electromyography, and postvoid residual urine measurement in cases who had urinary complaints on admission.

\section{Radiological Assessment}

All the included patients had a radiological assessment as MRI of the spine with cranial screening (in the setting of spinal dysraphism). Additional information was gathered from X-ray, ultrasound (US) and CT scan of the spine, in select cases, to document the pathological spectrum of spinal dysraphism.

\section{Surgical Intervention}

All the included patients underwent the standard laminectomy or laminoplasty. Lesions which extended longitudinally over a span of three or less vertebral segments were labeled as short while those spanning beyond three as long segment lesions. Patients of spinal dysraphism who had hydrocephalus and associated Chiari malformation were subjected to ventriculoperitoneal shunt. The definitive surgical decompression of inclusion cyst was performed during the same admission. From 2015 onward, we conducted all these surgeries under intraoperative electrophysiological monitoring system (Natus, Ontario, Canada). In a few select cases, the minimally invasive spine surgery (MISS) technique, (Destandeu's technique/microscopic tubular retractor system) was applied. The surgical time as well as blood loss encountered during excision of these lesions were noticed from the operation room record-keeping system.

\section{Postoperative Evaluation}

Postoperative assessment of sensory-motor changes, orthopedic deformity/disability, as well as bladder and bowel functions were compared with the preoperative status. The follow-up radiological investigation was performed after 3 months of surgery. Clinical and radiological evaluation with close correlation were conducted in subsequent visits to look for the residual or recurrent lesions.

\section{Statistical Analysis}

Statistical analysis was done by using SPSS for Windows software 19.0 (SPSS Inc. Chicago). The parametric data were expressed as mean/median and nonparametric data were expressed as number $(n)$ and percentage. Parametric data were analyzed using $t$-test, while the categorical data were analyzed using the Chi-square test. The $p$ value $<0.05$ was considered significant.

\section{Results}

\section{Demographic Profile}

A total of 73 patients was included in this study. The mean age of the patients in our study was $22.4 \pm 13.3$ years (range: 1 year to 56 years). Males $(n=47,64.4 \%$ ) outnumbered females ( $n=26,35.6 \%)$ among the study population. A total of $24(32.9 \%)$ dermoid and 49 (67.1\%) epidermoid cysts comprised the study subjects. We noticed approximately 8 folds higher incidence of epidermoids $(n=23)$ in females than 
dermoids ( $n=3)$. In this study, $44(60.3 \%)$ patients presented in their 2nd and 3rd decades, while 13 (17.8\%) patients were diagnosed during the first decade of life. Eleven patients of epidermoid and 5 cases of dermoid were noticed during 4 th to 6th decade, which reflects a delayed presentation of the pathology (-Table 1).

\section{Distribution of Lesion}

The most common location was the lumbosacral region followed by the thoracolumbar accounting for $41.1 \%(n=30)$ and $31.5 \%(n=23)$ cases, respectively. Additionally, $16(21.9 \%)$ had a midthoracic location and the sacral area (S2-S5) was involved in 3 (4.1\%) patients. Only one patient in our series had a cervical SDEC. The distribution of SDEC in the sacral region ( $n=3$ ) was one-tenth as compared with the lumbosacral region $(n=30, p=0.03)$. A total of $43(58.9 \%)$ patients had short segment lesion, while 30 (41.1\%) patients showed long segment involvement (-Table $\mathbf{1}$ ).

\section{Clinical Presentation}

A total of 32 patients (43.8\%) were self-ambulant and 26 patients (35.6\%) were able to walk with supports (25single person and 1-two person's support). Fifteen patients were chairbound or bedridden at presentation. The most common sensory complaint was the localized pain, noticed in $48(65.7 \%)$ patients, followed by the radicular pain in 17 (23.3\%) patients. This radicular pain was more profound in epidermoids, $13 / 17$ (76.5\%) cases as compared with the dermoids, 4/17 (23.5\%) cases ( $p=0.45$; - Table 2).

Fifty (68.5\%) patients presented with bladder dysfunction, while 16 (21.9\%) patients had simultaneous bowel involvement. Out of these, $18 / 50$ (36\%) patients complained of urinary retention, 24/50 (48\%) had frank urinary incontinence, while an increased urinary frequency was reported by $8 / 50(16 \%)$ patients. Bladder involvement was more frequent in epidermoids $31 / 50(62 \%)$ as compared with the dermoids $19 / 50$ (38\%) ( $p=0.19)$.

At admission, 16 (21.9\%) patients had bowel complaints in the form of constipation 6/16 (37.5\%) and involuntary passage of stool in 10/16 (62.5\%) patients. These bowel complaints were significantly more common with dermoids, 9/16 (56.3\%) cases as compared with epidermoids, 7/16 $(43.7 \%)$ cases $(p=0.03)$.

\section{Associated Mesodermal Defects/Spinal Dysraphism}

Kyphoscoliosis was noticed in 4 (5.5\%) patients with dermoids in the thoracolumbar region. Foot deformity was reported in $8(10.9 \%)$ patients in the form of equines varus and valgus deformity. Three patients were diagnosed to have a single kidney and two with atrophied uterus during MRI of the spine. A wide spectrum of pathology associated with neural tube defects was noticed in our series ( - Table 3 ). These include the following:

- Myelomeningocele, $n=3$.

- Lipomyelomeningocele, $n=10$.

- Lipomeningocele, $n=4$.

- Spinal cord lipoma with thickened filum, $n=4$.

- Thickened filum terminale, $n=16$.

- Split cord malformation (SCM) with thickened filum, $n=2$.

- Dermal sinus, $n=12$.

\section{Operative Intervention}

All the included patients underwent surgical decompression using microsurgical techniques. A total of 56 patients

Table 1 Demographic profile

\begin{tabular}{|c|c|c|c|}
\hline \multicolumn{2}{|l|}{$\begin{array}{l}\text { Total no. of patients }(N) \\
73\end{array}$} & $\begin{array}{l}\text { Numbers in dermoid }(n) \\
24\end{array}$ & $\begin{array}{l}\text { Numbers in epidermoid }(n) \\
49\end{array}$ \\
\hline \multicolumn{4}{|l|}{ Age (years) } \\
\hline $1-10$ & 13 & 7 & 6 \\
\hline $11-20$ & 28 & 10 & 18 \\
\hline $21-30$ & 16 & 2 & 14 \\
\hline $31-40$ & 6 & 3 & 3 \\
\hline $41-50$ & 8 & 1 & 7 \\
\hline $51-60$ & 2 & 1 & 1 \\
\hline \multicolumn{4}{|l|}{ Gender } \\
\hline Male & 47 & 21 & 26 \\
\hline Female & 26 & 3 & 23 \\
\hline \multicolumn{4}{|l|}{ Location } \\
\hline Cervical & 1 & 1 & 0 \\
\hline Thoracic (Upper + lower) & 16 & 1 & 15 \\
\hline $\begin{array}{l}\text { Thoracolumbar (thoracic + upper } \\
\text { lumbar, L2) }\end{array}$ & 23 & 10 & 13 \\
\hline $\begin{array}{l}\text { Lumbosacral (lumbar+ upper } \\
\text { sacral, S1) }\end{array}$ & 30 & 9 & 21 \\
\hline Sacral (S2-S4) & 3 & 3 & 0 \\
\hline
\end{tabular}


Table 2 Clinical spectrum of the disease

\begin{tabular}{|c|c|c|c|}
\hline Clinical presentation & Total no. (n) & Numbers in dermoid $(n)$ & Numbers in epidermoid $(n)$ \\
\hline \multicolumn{4}{|l|}{ Sensory complaints } \\
\hline Pain & 48 & 18 & 30 \\
\hline Localized pain & 31 & 14 & 17 \\
\hline Cervical & 1 & 1 & 0 \\
\hline Thoracic & 4 & 0 & 4 \\
\hline Localized back pain & 26 & 13 & 13 \\
\hline Radicular Pain & 17 & 4 & 13 \\
\hline Unilateral radicular pain & 7 & 2 & 5 \\
\hline Bilateral radicular pain & 10 & 2 & 8 \\
\hline Localized pain + radicular pain & 7 & 1 & 6 \\
\hline Numbness in lower limbs & 55 & 19 & 36 \\
\hline Paresthesia in lower limbs & 41 & 19 & 22 \\
\hline \multicolumn{4}{|l|}{ Motor complaints } \\
\hline Self-ambulant & 32 & 12 & 20 \\
\hline $\begin{array}{l}\text { Ambulant with stick or a person's } \\
\text { support }\end{array}$ & 25 & 9 & 16 \\
\hline Ambulant with two persons support & 1 & 0 & 1 \\
\hline Chairbound/bedridden & 15 & 2 & 13 \\
\hline
\end{tabular}

Table 3 Neurocutaneous and autonomic dysfunctions in SDEC

\begin{tabular}{|c|c|c|c|}
\hline Associated anomalies & Total no. (n) & Numbers in dermoid $(n)$ & Numbers in epidermoid $(n)$ \\
\hline Neural tube defects & 20 & 12 & 8 \\
\hline \multicolumn{4}{|l|}{ Cutaneous stigmata } \\
\hline Hypertrichosis & 10 & 7 & 3 \\
\hline Subcutaneous lipoma & 16 & 10 & 6 \\
\hline Hyperpigmented skin & 3 & 2 & 1 \\
\hline Dermal Sinus & 12 & 7 & 5 \\
\hline \multicolumn{4}{|l|}{ Urinary bladder involvement } \\
\hline Retention of urine & 18 & 8 & 10 \\
\hline Urinary incontinence & 24 & 9 & 15 \\
\hline Increased frequency & 8 & 2 & 6 \\
\hline Bowel involvement & 16 & 9 & 7 \\
\hline Constipation & 6 & 5 & 1 \\
\hline Involuntary defecation & 10 & 4 & 6 \\
\hline
\end{tabular}

underwent total excision (more than 95\% decompression microscopically and radiologically), while in 17 cases, subtotal excision (80-95\% decompression) was achieved. The intradural extramedullary (IDEM) lesions in horizontal plane contribute toward the majority of the surgical candidates (-Table 4). Intraoperative neuromonitoring (IONM) was performed in 16 cases. The mean blood loss during decompression of dermoid was $270.8 \pm 106.2 \mathrm{~mL}$ as compared with epidermoid which was $257.1 \pm 109.4 \mathrm{~mL}(p=0.45)$. The surgical time for excision of dermoids was $3.2 \pm 1.2$ hours as compared with epidermoids $2.9 \pm 0.9$ hours ( $p=0.35$ ). Surgical time ( $3.6 \pm 0.6$ hours vs. $2.6 \pm 0.6$ hours) as well as blood loss $(445 \pm 194.6 \mathrm{~mL}$ vs $294.9 \pm 86.7 \mathrm{~mL}$ ) were significantly higher $(p=0.003)$ in SDEC with spinal dysraphism versus SDEC without dysraphism. Cerebrospinal fluid (CSF) leak was noticed in 4 patients which were managed with re-exploration and repair of the defect.

\section{Postoperative Follow-up}

At 3-months follow-up evaluation, 14 of the 41 patients (34.1\%), who had gait related problems, showed remarkable improvement in their gait, and 32 patients who were ambulant and intact remained so (-Table 5). Motor power (Medical Research Council [MRC] scale) improved by at least 1 grade in 29 of 41 patients (70.7\%) with motor deficits. Forty patients (of the 48 who had pain preoperatively, 83.3\%) improved to normal or near-normal neurologic status and 25 patients who were free from sensory complaints were intact and remained so ( - Table 5 ). There was no surgery-related mortality in the study. Mean duration of 
Table 4 Radiological assessment of SDECs

\begin{tabular}{|c|c|c|c|}
\hline Radiological finding & Total no. (n) & Numbers in dermoid $(n)$ & Numbers in epidermoid $(n)$ \\
\hline \multicolumn{4}{|l|}{ Bone-related anomalies } \\
\hline Vertebral defect & 29 & 8 & 21 \\
\hline Foot deformity & 8 & 5 & 3 \\
\hline Vertebral and foot deformity & 5 & 3 & 2 \\
\hline Kyphoscoliotic deformity & 4 & 1 & 3 \\
\hline \multicolumn{4}{|l|}{$\begin{array}{l}\text { Location of tumor } \\
\text { (according to horizontal plane) }\end{array}$} \\
\hline Intramedullary & 15 & 9 & 6 \\
\hline IDEM & 45 & 10 & 35 \\
\hline $\begin{array}{l}\text { Transitional (both intra and extradural } \\
\text { components) }\end{array}$ & 8 & 3 & 5 \\
\hline Extradural & 5 & 2 & 3 \\
\hline Syrinx & 18 & 8 & 10 \\
\hline Cervical & 1 & 1 & 0 \\
\hline Thoracic & 13 & 9 & 4 \\
\hline Lumbar & 4 & 3 & 1 \\
\hline \multicolumn{4}{|l|}{ Vertebral segments involved } \\
\hline $\begin{array}{l}\text { Short segment (up to } 3 \text { vertebral segments } \\
\text { involved) }\end{array}$ & 43 & 12 & 31 \\
\hline $\begin{array}{l}\text { Long segment (more than } 3 \text { vertebral segments } \\
\text { involved) }\end{array}$ & 30 & 12 & 18 \\
\hline Visceral anomaly (single kidney) & 3 & 1 & 2 \\
\hline
\end{tabular}

Abbreviations: IDEM, intradural extramedullary; SDECs, spinal dermoid and epidermoid cysts.

Table 5 Follow-up clinical evaluation

\begin{tabular}{|c|c|c|c|}
\hline Extent of Resection & $\begin{array}{l}\text { Total No. }(n) \\
(73)\end{array}$ & $\begin{array}{l}\text { Numbers in dermoid }(n) \\
(24)\end{array}$ & $\begin{array}{l}\text { Numbers in epidermoid }(n) \\
(49)\end{array}$ \\
\hline Complete resection & 56 & 14 & 42 \\
\hline Subtotal resection & 17 & 10 & 7 \\
\hline \multicolumn{4}{|l|}{ Motor symptoms (gait) } \\
\hline Preoperative & 41 & 11 & 30 \\
\hline Postoperative & 27 & 10 & 17 \\
\hline \multicolumn{4}{|l|}{ Sensory symptoms } \\
\hline Preoperative & 48 & 18 & 30 \\
\hline Postoperative & 8 & 5 & 3 \\
\hline \multicolumn{4}{|l|}{ Bladder complaints } \\
\hline Preoperative & 50 & 19 & 31 \\
\hline Postoperative & 27 & 11 & 16 \\
\hline \multicolumn{4}{|l|}{ Bowel complaints } \\
\hline Preoperative & 16 & 9 & 7 \\
\hline Postoperative & 5 & 5 & 0 \\
\hline
\end{tabular}

follow-up was 30.4 \pm 27.1 months (range: 6-120 months). Till the last follow-up, either physical or on cellular phone, eight patients were readmitted with recurrence (5-dermoid cysts, 3-epidermoid cysts) and were subjected to re-excision. Three patients (3/73) lost to follow-up over the course of study.

\section{Discussion}

\section{Embryological Background}

The basic explanation for the SDEC accepted to date is abnormal implantation of ectodermal and/or mesodermal rests during the process of primary neurulation. The primary 
neurulation in human is a highly organized, rapidly evolving morphogenetic event during the 4 th week of gestation. ${ }^{8-10}$

\section{Continuous Closure Model}

So far, the most accepted model is where the closure starts between the 3rd and 6th somite and proceeds in a zipper-like manner. The fusion of dorsal and ventral lips marks the closure of rostral neuropore, which gets completed in the fourth week of gestation, followed by separation of the surface ectoderm from the neural ectoderm. ${ }^{6}$ The disturbed separation process could lead to abnormal inclusion of surface ectodermal (epidermoid cyst) and/or mesodermal structures (dermoid). The final closure of caudal neuropore occurs at the level of somite 31 (future second sacral vertebra) or 32 to 34 (future third and fourth sacral vertebrae).

\section{Multisite Closure Model}

Von Allen et al found that the mouse multi-site neural tube closure model could best explain the human neural tube defect. They proposed the five closure sites for the developing neural tube ( - Fig. 1). ${ }^{2}$ Nakatsu et al supported this multisite closure model with major influence from Kyoto Collection of human embryos ( - Fig. 2)..$^{711-13}$

\section{Clinical Extrapolation of Neural Tube Closure Models}

The neurocutaneous stigmata and bladder dysfunction serve as clinical markers of underlying spinal cord pathology. The multisite closure model explains some specific sites of this inclusion cyst; mainly, the lower cervical, upper thoracic,

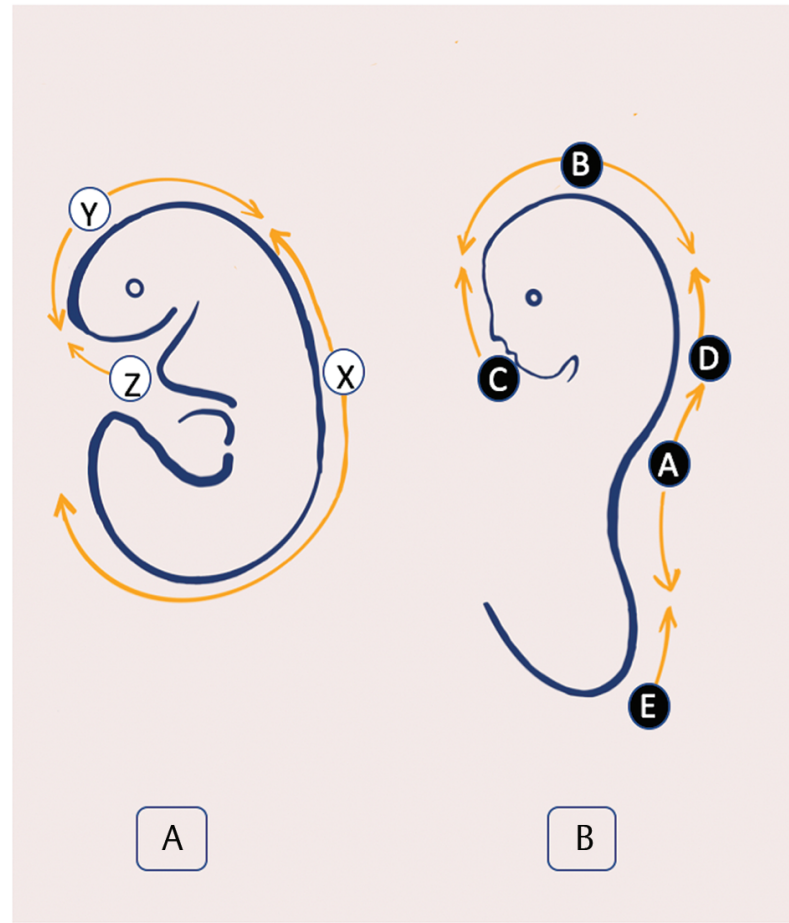

Fig. 1 Diagram representing order of events involved in primary neurulation. (A) The craniocaudal neurulation events involved in mouse embryo. $\mathrm{X}, \mathrm{Y}$, and $\mathrm{Z}$ marks the initiation of closure sites. (B) The Van Allen et al model reflecting the multisite closure in mouse embryos. The beginning of closure sites are recognized as A, $B, C, D$ and $E$.

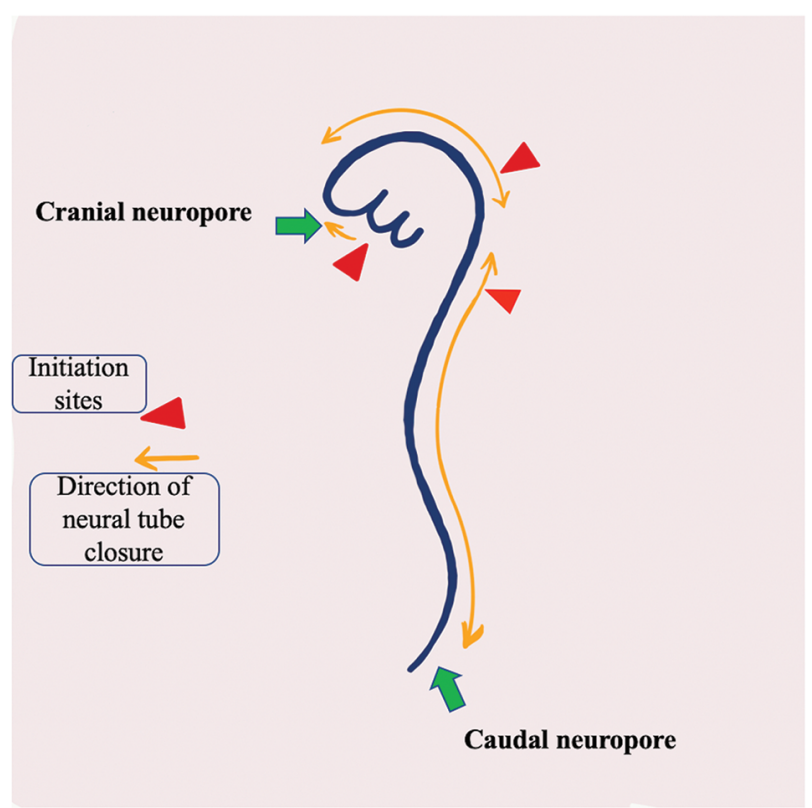

Fig. 2 Diagram showing multisite closure model in human embryo. The red triangles are reflecting three initiation sites of neural tube closure ( 1 indicates the cervical level, 2 represents the mesencephalo-rhombencephalic boundary, and 3 indicates the cranial end of neural groove) and yellow color arrows indicate the directions of neural tube closure. The green arrows indicate the sites of cranial and caudal neuropore.

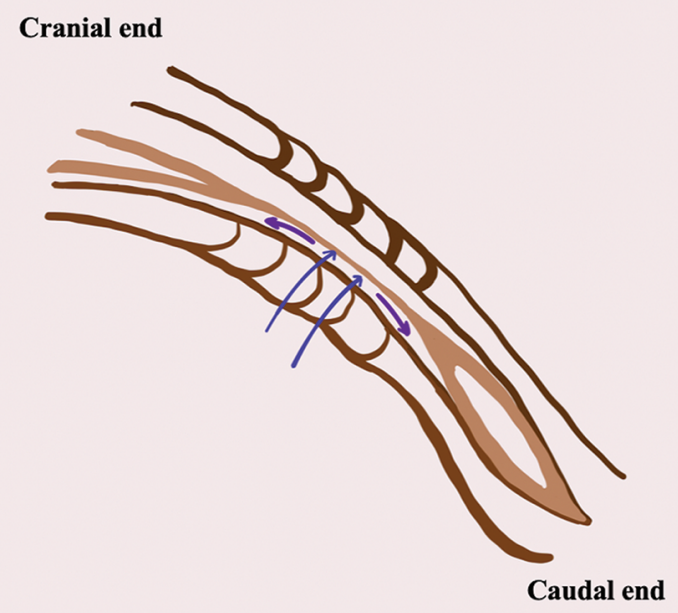

Fig. 3 Diagram showing secondary neurulation in human embryo. Double blue arrows point toward the filum terminale, and upward-going purple arrow points toward the conus medullaris. The downward-pointed purple arrow indicates the terminal dilatation of the central canal known as ventriculus terminalis.

thoracolumbar, and lumbosacral regions. The lesion over these sites contribute a major proportion of our cases $(n=46)$ and therefore seem to be validated by our findings. On the other hand, the sequential events of continuous closure model imply that the outcome of defective closure 


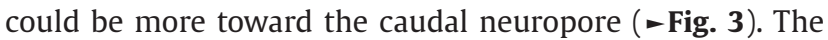
clinical findings in our series suggest the lower occurrence of SDEC at S2-S4 $(n=3)$, which is $\sim 10$ times less common as compared with the one at lumbosacral region (L-S1) $(n=30)$. The defects associated with neural tube closure are clinically more widespread in dermoids as compared with epidermoids..$^{14,15}$

\section{Demographic and Clinical Spectrum}

Dermoid cysts are diagnosed more frequently in the younger age group as compared with the epidermoids. ${ }^{8,16,17}$ In the present study, 57 patients were symptomatic before the completion of the third decade of life. The present study favors male predominance, which is in conjunction with the available literature. ${ }^{18}$ Cases diagnosed in early life had obvious clinical conditions like foot deformity and or spinal dysraphism. Bony deformities in the form of hemivertebra and Klippel-Feil syndrome are well documented. ${ }^{19,20}$ Several case series support the occurrence of spine curvature anomalies in patients of spinal dysraphism. ${ }^{21-23}$ Pain, being the most common presenting complaints, may be radicular, myelopathic or localized due to dural stretching and altered osteoligamentous biomechanics because of scoliotic deformity. ${ }^{24}$

The pathology located at intramedullary and thoracolumbar regions manifests early with bladder and bowel complaints. The neurocutaneous markers are often a dependable indicator of an underlying dysraphic state. Discharging or infected sinus drags early attention toward the concealed pathology with dysraphism. The anatomical location and natural growth pattern reveal their clinical picture. ${ }^{22,25-27}$ In our study, two discharging dermal sinuses were noticed without any rupture. SDECs are distributed in intramedullary, IDEM, extradural and, even, subcutaneous planes or at any point along the dermal sinus tract. ${ }^{28-31}$ If accidental rupture happens in these SDECs, either spontaneous or during surgery, intense chemical meningitis ensues if extravasation of their contents is not dealt promptly. ${ }^{32}$ Intracranial extension of cyst material have been reported in literature and basic treatment relies on control the escalating intracranial pressure and avoid ongoing inflammation.

\section{Intraoperative Neurophysiology and Surgical Nuances}

The dense adhesion of the cyst wall to the neural structures precludes complete elimination of these lesions from the spinal cord and traversing nerve roots. ${ }^{33}$ Associated neural tube defects increase the complexity of maneuver due to direct handling of placode, tethered nerve roots as well as the fibrous or bony septum. Patients of Chiari II malformation are prone to develop hydrocephalus as well as tonsillar herniation, and they were subjected to additional surgery before tumor decompression. Although osteoplastic laminotomy decreases the risk of epidural fibrosis, their role in the prevention of spinal deformity is equivocal, as suggested by Wiedemayer et al. ${ }^{34}$ It is a well-accepted fact that decompression of spinal cord lesion under neuromonitoring has resulted in the better postoperative outcome as compared with those operated without monitoring. ${ }^{35-37}$ Intraoperative assessment of lower limbs somatosensory-evoked potential (SSEP), motor-evoked potential (MEP) along with spontaneous/stimulated electromyography (EMG) activity in external anal sphincter are considered as the standard of care in modern days. ${ }^{38}$

The adhered cyst wall remnants act as a nidus for recurrence which indeed is more difficult to treat; being slow-growing pathology, symptomatic recurrence from such lesions involves several years of latency period. ${ }^{39}$ Spillage of cyst contents due to intraoperative rupture provides a fertile ground for aseptic meningitis to develop. ${ }^{40}$

There were $83.3 \%$ (40/48) sensory improvement and 68.7\% $(11 / 16)$ recovery in bowel function at the time of last follow-up ( $\mathbf{- F i g s . ~} 4$ and $\mathbf{5}$ ). In the present study, more than

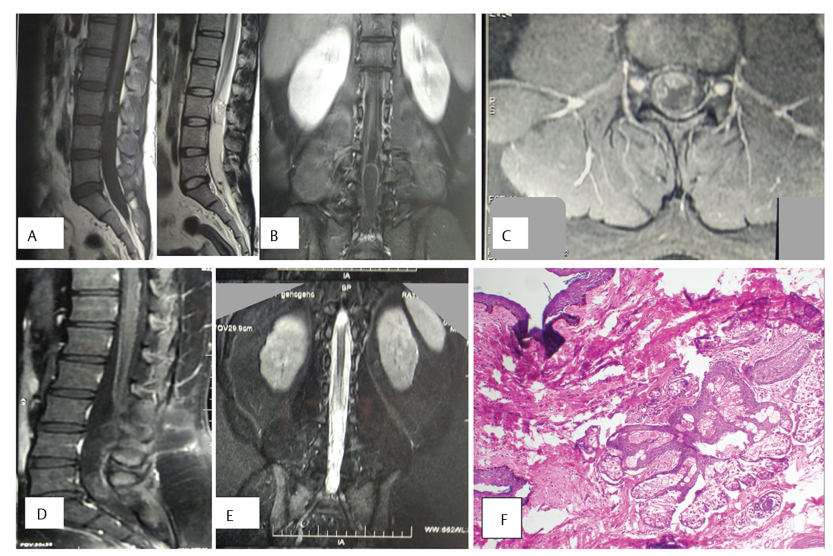

Fig. 4 (A-C) Preoperative MRI scan, showing low-lying conus ending at L2-L3 disc space with heterogenous hypointensity on T1WI and hyperintensity on T2WI. (D) and (E) Postoperative scan showing no residual lesion. (F) Hematoxylin and eosin-stained section shows tissue lined by stratified squamous epithelium, with subepithelium showing clusters of sebaceous glands (100X), suggestive of dermoid.
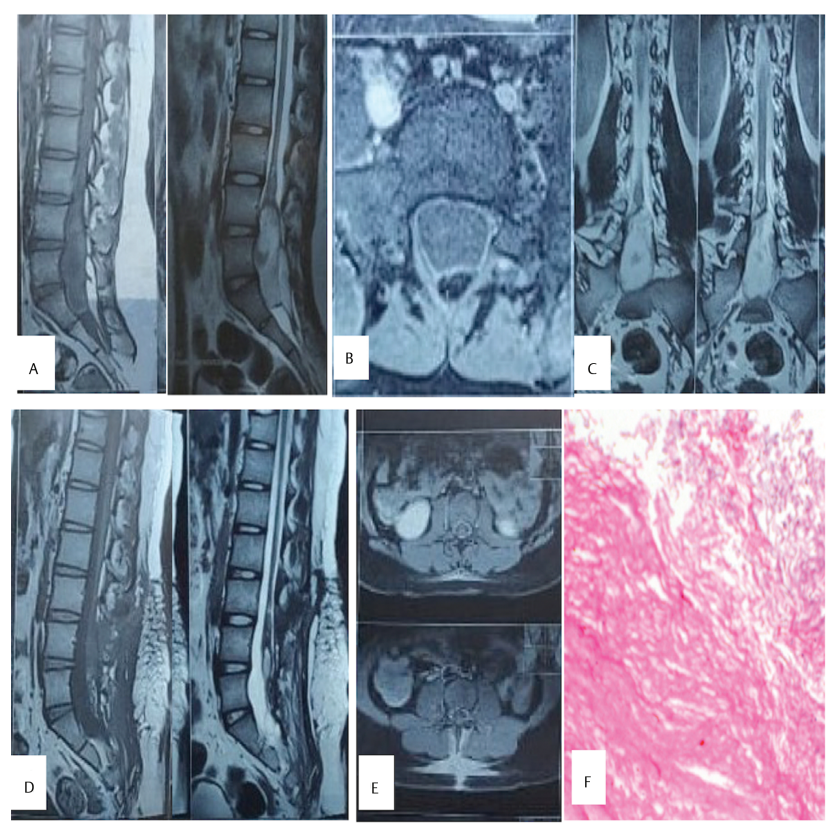

Fig. 5 (A-C) Preoperative MRI scan lobulated lesion, hypointense on T1WI, while heterogeneously hyperintense on T2WI from L3 to S2, displacing conus and nerve roots. (D) and (E) Postoperative scan showing no obvious residual lesion. (F) Hematoxylin and eosinstained section shows fibrous wall containing abundant keratin flakes (200X), suggestive of epidermoid. 
three-fourth of the cases underwent total excision with a favorable outcome. A low threshold for maximum safe surgical resection should be the goal in these benign lesions where complete eradication is difficult to obtain. Long-term follow-up with annual spine MRI is recommended to diagnose the early recurrence.

\section{Limitations}

The present work is a retrospective observational study, and lost to follow-up is a common occurrence in this duration (20 years), although we did not encounter such problem to greater extent because of meticulous record-keeping system. Subgroup comparison and analysis could have been performed better with a larger sample size, a practical limitation, which mandates a future prospective study.

\section{Conclusion}

The spinal inclusion cysts require long-term follow-up to identify the protracted clinical course of the disease. The presence of spinal dysraphism in the background of SDEC increases the complexity of surgical management of these lesions. The results of our study support the multisite closure model and attempts to provide a retrospective reflection of neural tube closure model in humans by using SDEC as the surrogate marker of neural tube closure defect.

\section{Funding}

None.

\section{Conflict of Interest}

None declared.

\section{References}

1 Roux A, Mercier C, Larbrisseau A. Dube LJ, Dupuis C, Del Carpio $R$. Intramedullary epidermoid cysts of the spinal cord. Case report. J Neurosurg 1992;76(3):528-533

2 Van Allen MI, Kalousek DK, Chernoff GF, et al. Evidence for multi-site closure of the neural tube in humans. Am J Med Genet 1993;47(5):723-743

3 Golden JA, Chernoff GF. Anterior neural tube in the mouse: fuel for disagreement with the classical theory. Clin Res 1983;31:127A

4 Juriloff DM, Harris MJ, Tom C, MacDonald KB. Normal mouse strains differ in the site of initiation of closure of the cranial neural tube. Teratology 1991;44(2):225-233

5 van Straaten HWM, Peeters MCE, Hekking JWM, van der Lende T. Neurulation in the pig embryo. Anat Embryol (Berl) 2000;202(2):75-84

6 O'Rahilly R, Müller F. Neurulation in the normal human embryo. Ciba Found Symp 1994;181:70-82, discussion 82-89

7 Nakatsu T, Uwabe C, Shiota K. Neural tube closure in humans initiates at multiple sites: evidence from human embryos and implications for the pathogenesis of neural tube defects. Anat Embryol (Berl) 2000;201(6):455-466

8 Shikata J, Yamamuro T, Mikawa Y, Kotoura Y. Intraspinal epidermoid and dermoid cysts. Surgical results of seven cases. Arch Orthop Trauma Surg 1988;107(2):105-109

9 Netsky MG. Epidermoid tumors. Review of the literature. Surg Neurol 1988;29(6):477-483
10 Van Gilder JC, Schwartz HG. Growth of dermoids from skin implants to the nervous system and surrounding spaces of the newborn rat. J Neurosurg 1967;26(1):14-20

11 Golden JA, Chernoff GF. Intermittent pattern of neural tube closure in two strains of mice. Teratology 1993;47(1):73-80

12 Sakai Y. Neurulation in the mouse: manner and timing of neural tube closure. Anat Rec 1989;223(2):194-203

13 Nishimura H, Prenatal versus postnatal malformations based on the Japanese experience on induced abortions in the human being. In: Blandau RJ, ed. Aging gametes. Basel: Karger; 1975: 349-368

14 Gonzalvo A, Hall N, McMahon JHA, Fabinyi GC. Intramedullary spinal epidermoid cyst of the upper thoracic region. J Clin Neurosci 2009;16(1):142-144

15 Cincu R, Lázaro JF, Liesa JL, Callizo JR. Dorsal intramedullary spinal epidermoid cysts: report of two cases and review of literature. Indian J Orthop 2007;41(4):395-397

16 Zavanone M, Guerra P, Rampini PM, Crotti F, Vaccari U. A cervicodorsal intramedullary epidermoid cyst. J Neurosurg Sci 1991;35:111-115

17 Guidetti B, Gagliardi FM. Epidermoid and dermoid cysts. Clinical evaluation and late surgical results. J Neurosurg 1977;47(1):12-18

18 Falavigna A, Righesso O, Teles AR. Concomitant dermoid cysts of conus medullaris and cauda equina. Arq Neuropsiquiatr 2009;67(2A) :293-296

19 Sun JC, Steinbok P, Cochrane DD. Cervical myelocystoceles and meningoceles: long-term follow-up. Pediatr Neurosurg 2000;33(3):118-122

20 Orakdogen M, Turk CC, Ersahin M, Biber N, Berkman Z. Spinal dysraphisms of the cervicothoracic region in childhood. Turk Neurosurg 2009;19(4):400-405

21 Myles LM, Steers AJ, Minns R. Cervical cord tethering due to split cord malformation at the cervico-dorsal junction presenting with self-mutilation of the fingers. Dev Med Child Neurol 2002;44(12):844-848

22 Pang D, Zovickian J, Oviedo A, Moes GS. Limited dorsal myeloschisis: a distinctive clinicopathological entity. Neurosurgery 2010;67(6):1555-1579, discussion 1579-1580

23 Pessoa BL, Lima Y, Orsini M. True cervicothoracic meningocele: a rare and benign condition. Neurol Int 2015;7(3):6079

24 Sewell MJ, Chiu YE, Drolet BA. Neural tube dysraphism: review of cutaneous markers and imaging. Pediatr Dermatol 2015;32(2):161-170

25 Liu H, Zhang JN, Zhu T. Microsurgical treatment of spinal epidermoid and dermoid cysts in the lumbosacral region. J Clin Neurosci 2012;19(5):712-717

26 van Aalst J, Beuls EAM, Cornips EMJ, et al. Anatomy and surgery of the infected dermal sinus of the lower spine. Childs Nerv Syst 2006;22(10):1307-1315

27 Kanev PM, Park TS. Dermoids and dermal sinus tracts of the spine. Neurosurg Clin N Am 1995;6(2):359-366

28 Mohindra S, Gupta R, Chhabra R, et al. Infected intraparenchymal dermoids: an underestimated entity. J Child Neurol 2008;23(9):1011-1016

29 Chen CY, Lin KL, Wang HS, Lui TN. Dermoid cyst with dermal sinus tract complicated with spinal subdural abscess. Pediatr Neurol 1999;20(2):157-160

30 van Aalst J, Hoekstra F, Beuls EAM, et al. Intraspinal dermoid and epidermoid tumors: report of 18 cases and reappraisal of the literature. Pediatr Neurosurg 2009;45(4):281-290

31 Barkovich AJ, Edwards MS, Cogen PH. MR evaluation of spinal dermal sinus tracts in children. AJNR Am J Neuroradiol 1991;12(1):123-129

32 Liu JK, Gottfried ON, Salzman KL, Schmidt RH, Couldwell WT. Ruptured intracranial dermoid cysts: clinical, radiographic, 
and surgical features. Neurosurgery 2008;62(2):377-384, discussion 384

33 Sandalcioglu IE, Gasser T, Asgari S, et al. Functional outcome after surgical treatment of intramedullary spinal cord tumors: experience with 78 patients. Spinal Cord 2005;43(1):34-41

34 Wiedemayer H, Sandalcioglu IE, Aalders M, Wiedemayer H, Floerke M, Stolke D. Reconstruction of the laminar roof with miniplates for a posterior approach in intraspinal surgery: technical considerations and critical evaluation of follow-up results. Spine 2004;29(16):E333-E342

35 Velayutham P, Cherian VT, Rajshekhar V, Babu KS. The effects of propofol and isoflurane on intraoperative motor evoked potentials during spinal cord tumour removal surgery - A prospective randomised trial. Indian J Anaesth 2019;63(2):92-99

36 Ali Z, Bithal PK. Intra-operative neurophysiological monitoring. J Neuroanaesth Crit Care 2015;2:179-192
37 Deletis V, Sala F. Intraoperative neurophysiological monitoring of the spinal cord during spinal cord and spine surgery: a review focus on the corticospinal tracts. Clin Neurophysiol 2008;119(2):248-264

38 Kelleher MO, Tan G, Sarjeant R, Fehlings MG. Predictive value of intraoperative neurophysiological monitoring during cervical spine surgery: a prospective analysis of 1055 consecutive patients. J Neurosurg Spine 2008;8(3):215-221

39 Constantini S, Miller DC, Allen JC, Rorke LB, Freed D, Epstein FJ. Radical excision of intramedullary spinal cord tumors: surgical morbidity and long-term follow-up evaluation in 164 children and young adults. J Neurosurg 2000;93(2,Suppl):183-193

40 Munshi A, Talapatra K, Ramadwar M, Jalali R. Spinal epidermoid cyst with sudden onset of paraplegia. J Cancer Res Ther 2009;5(4):290-292 